\title{
KEANEKARAGAMAN JENIS MAKROALGA YANG BERPOTENSI SEBAGAI BAHAN OBAT DI PERAIRAN PANTAI CIDATU KABUPATEN PANDEGLANG
}

\author{
Haris Shobir $^{1}$, Triastinurmiatiningsih ${ }^{1 *}$, Ismanto $^{1}$ \\ ${ }^{1}$ Program Studi Biologi FMIPA Universitas Pakuan, Bogor \\ *e-mail: triastinur@gmail.com
}

diterima: 20 Juli 2019; direvisi:22 Agustus 2019; disetujui: 3 September 2019

\begin{abstract}
ABSTRAK
Makroalga mempunyai berbagai jenis senyawa polisakarida diantaranya alginat, agar-agar, karaginan dan senyawa bioaktif serta mengandung pigmen yang berpotensi sebagai obat. Penelitian tentang keanekaragaman jenis makroalga yang berpotensi sebagai bahan obat di perairan Pantai Cidatu Kabupaten Pandeglang telah dilakukan. Penelitian dilakukan dengan metode transek. Lokasi pengambilan sampel dibedakan menjadi tiga stasiun. Setiap stasiun dibuat tiga transek dengan jarak antar transek $5 \mathrm{~m}$ dan setiap transek terdiri dari lima plot ukuran $1 \mathrm{x} 1 \mathrm{~m}$ dengan jarak antar plot $5 \mathrm{~m}$. Jenis makroalga yang berpotensi obat di perairan Pantai Cidatu berjumlah 10 spesies yaitu 3 spesies dari kelas Chlorophyceae (Ulva intestinalis, Ulva reticulata dan Chaetomorpha crassa), 4 spesies dari kelas Phaeophyceae (Padina australis, Turbinaria decurrens, Sargassum crassifolium, dan Sargassum polycystum) dan 3 spesies dari kelas Rhodophyceae (Gracilaria salicornia, Gracilaria coronopifolia dan Gelidium sp). Indeks keanekaragaman jenis pada pantai Cidatu yaitu 2,169 yang dikategorikan keaneakaragaman jenis sedang.
\end{abstract}

\section{Kata Kunci: Makroalga, Pantai Cidatu, keanekaragaman jenis \\ DIVERSITY OF MACROALGAE AS POTENTIAL MEDICINE IN COASTAL WATERS CIDATU DISTRICT PANDEGLANG}

\begin{abstract}
Macroalgae have various types of polysaccharides such as alginate, gelatin, and bioactive compounds and contain potential pigments as drugs. Research on the diversity of macroalgae types that are potentially as medicinal substances in the waters of Cidatu Beach Pandeglang has done. Research is done by transek method. Sampling locations are differentiated into three stations. Each station is made of three transect with a distance between $5 \mathrm{~m}$ and each transect consisting of five plots $1 \times 1 \mathrm{~m}$ with a distance between plots $5 \mathrm{~m}$. The potentially medicinal macroalgae in the waters of Cidatu are 10 species which are 3 species of the Chlorophyceae class (Ulva intestinalis, Ulva reticulata and Chaetomorpha crassa), 4 species of the class Phaeophyceae (Padina australis, Turbinaria decurrens, Sargassum crassifolium, and Sargassum polycystum) and 3 species of the class Rhodophyceae (Gracilaria salicornia, Gracilaria coronopifolia and Gelidium sp). The index of diversity in Cidatu beach is 2.169 which is categorized diversity moderate type.
\end{abstract}

Key words: macroalgae, pantai Cidatu, diversity of types 


\section{PENDAHULUAN}

Kabupaten Pandeglang merupakan salah satu kabupaten di Provinsi Banten yang diarahkan untuk berfungsi sebagai daerah penyangga DKI Jakarta dan sebagai daerah pengembangan kepariwisataan (Pratama et al, 2014). Salah satu obyek wisata alam yang berada di Kabupaten Pandeglang adalah Pantai Cidatu. Pantai Cidatu merupakan salah satu kawasan pariwisata yang secara administratif terletak di Kecamatan Carita Kabupaten Pandeglang, Banten. Perairan Pantai Cidatu diduga memiliki potensi sumber daya hayati laut yang cukup melimpah. Perairan pesisir pantai umumnya kaya akan keanekaragaman jenis biotanya, salah satunya adalah makroalga atau rumput laut.

Menurut Saptasari (2010) makroalga merupakan produsen pantai dan jenis-jenis yang ditemukan di pantai berbatu karang umumnya adalah dari kelas Chlorophyceae, Phaeophyceae, dan Rhodophyceae. Rumput laut dari kelas Rhodophyceae menempati urutan terbanyak dari jumlah jenis yang tumbuh di perairan laut Indonesia yaitu sekitar 452 jenis, setelah itu Chlorophyceae sekitar 196 jenis dan Phaeophyceae sekitar 134 jenis (Winarno, 1996).

Insan dan Widyartini (2008) menyatakan tumbuhan yang digunakan sebagai obat selama ini kebanyakan dari tumbuhan darat sedangkan tumbuhan yang berasal dari laut seperti makroalga belum banyak mendapat perhatian. Makroalga mempunyai berbagai jenis senyawa polisakarida diantaranya alginat, agar-agar, karaginan dan senyawa bioaktif serta mengandung pigmen. Makroalga mempunyai tiga jenis pigmen utama, yaitu klorofil, karotenoid, dan fikosianin. Setiap jenis pigmen tersebut mempunyai berbagai manfaat khususnya bagi kesehatan (Merdekawati, 2009).

Tinggi atau rendahnya tingkat keanekaragaman jenis makroalga akan ditentukan dengan menggunakan rumus index Shannon-Wienner (H') dan menghitung nilai parameter pendukung yaitu intensitas cahaya, suhu, salinitas dan pH. Nilai dari indeks keanekaragaman jenis makroalga kemudian dikategorikan tinggi apabila $\left(\mathrm{H}^{\prime}\right)>3$, keanekaragaman jenis sedang apabila $1 \leq\left(\mathrm{H}^{\prime}\right) \leq 3$, dan keanekaragaman jenis rendah apabila $\left(\mathrm{H}^{\prime}\right)$ $<$ 1. Untuk mengetahui jenis-jenis makroalga yang berada di perairan pantai Cidatu sebagai obat maka ditentukan dengan studi literatur.

Mengingat akan kekayaan alam yang terkandung di lautan, khususnya di pantai dan penelitian terhadap makroalga atau rumput laut di kawasan pantai wisata Cidatu masih belum dilakukan maka sebagai langkah awal penggalian sumber hayati laut diteliti keanekaragaman jenis makroalga yang berpotensi sebagai bahan obat yang berada di perairan Pantai Cidatu Kabupaten Pandeglang.

\section{BAHAN DAN METODE}

Penelitian telah dilaksanakan pada bulan November hingga Januari 2017 di perairan Pantai Cidatu Kecamatan Carita Kabupaten Pandeglang.

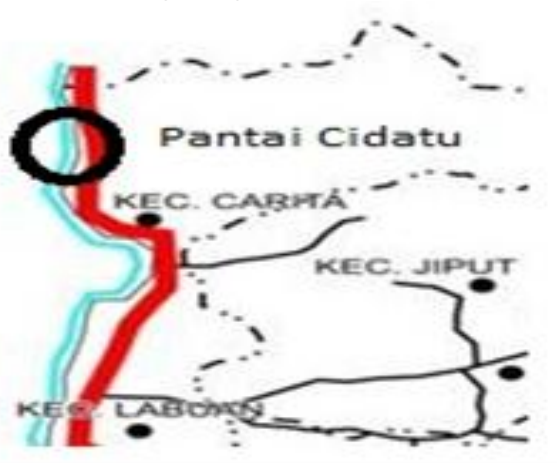

Gambar 1. Peta lokasi penelitian

(Subagja, 2010). Ket: Gambar telah diperbesar dari aslinya.

Penelitian ini dilakukan dengan 3 tahap yaitu 1) Pengambilan sampel 2) Identifikasi sampel 3) Inventarisasi potensi makroalga sebagai obat.

\section{Pengambilan Sampel}

Lokasi pengambilan sampel dibedakan menjadi tiga stasiun untuk intensitas sampling 1\% yang berada pada 
wilayah pasang surut (intertidal). Jarak antara satu stasiun dengan stasiun lainnya adalah sejauh 30 meter agar penelitian dapat mewakili luas pantai Cidatu. Setiap stasiun tersebut ditetapkan tiga transek dengan jarak antar transek $5 \mathrm{~m}$. Setiap transek terdiri dari lima plot $1 \mathrm{x} 1 \mathrm{~m}$ dengan jarak antar plot 5 meter (Gambar 2) (English dkk., 1994).

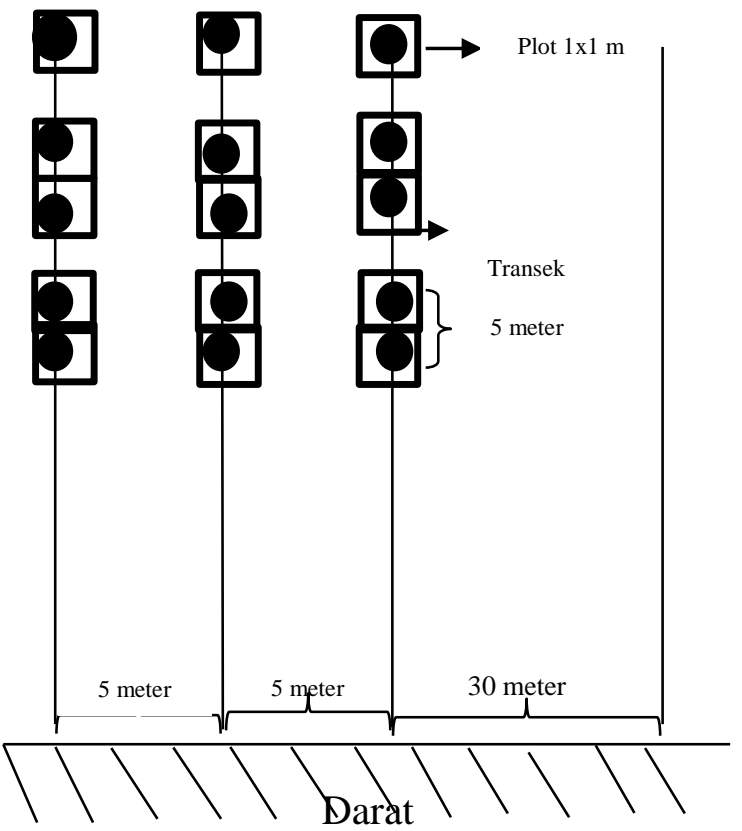

Gambar 2. Teknik Sampling Metode Transek

Makroalga yang terdapat pada setiap plot dicatat keberadaannya dan dilakukan koleksi (Stephani dkk., 2014). Pada setiap sampel makroalga diawetkan dengan cara merendam alga laut ke dalam alkohol $70 \%$ untuk kepentingan identifikasi. Sebelum diawetkan, dilakukan pengambilan gambar untuk mendokumentasikan warna dan morfologi karena umumnya makroalga berubah warna (Atmadja dkk., 1996).

\section{Identifikasi Sampel}

Sampel yang telah diambil kemudian diidentifikasi dengan mengamati sampel secara morfologi seperti bentuk, tekstur dan warna thallus. Buku yang digunakan acuan untuk mengidentifikasi sampel makroalga adalah buku Atmadja dkk., (1996), Kadi (2004), dan Sulistijo (2009).

\section{Inventarisasi Potensi Makroalga Sebagai Obat}

Potensi makroalga sebagai obat ditentukan dengan studi literatur dari Kadi dan Rachmaniar (1996) dan Kadi (2004).

\section{HASIL DAN PEMBAHASAN}

Berdasarkan hasil identifikasi yang telah dilakukan di perairan Pantai Cidatu Kabupaten Pandeglang diperoleh 12 jenis makroalga secara keseluruhan meliputi 3 jenis dari kelas Chlorophyceae, 5 jenis dari kelas Phaeophyceae dan 4 jenis dari kelas Rhodophyceae. Jenis-jenis makroalga tersaji pada Tabel 1 sebagai berikut:

Tabel 1. Jenis-jenis Makroalga yang Ditemukan di Perairan Cidatu Kabupaten Pandeglang

\begin{tabular}{clccc}
\hline \multirow{2}{*}{ Kelas } & \multicolumn{3}{c}{ Nama spesies } & \multicolumn{2}{c}{ Stasiun } & \\
\cline { 3 - 5 } & & I & II & III \\
\cline { 2 - 4 } Chlorophyceae & Ulva intestinalis & 266 & \multicolumn{1}{c}{ indv } & $\Sigma$ indv \\
& Ulva reticulate & 179 & 97 & 214 \\
& Chaetomorpha crassa & 143 & 66 & 51 \\
\hline Phaeophyceae & Padina australis & 129 & 138 & 43 \\
& Turbinaria conoides & 88 & 81 & 94 \\
& Turbinaria decurrens & 22 & 19 & 105 \\
& Sargassum polycystum & 44 & 194 & 155 \\
& Sargassum crassifolium & 39 & 157 & 143 \\
\hline Rhodophyceae & Gracillaria salicornia & 30 & 39 & 27 \\
& Gelidium sp. & 28 & 35 & 17 \\
& Gracilaria coronopifolia & 3 & 19 & 7 \\
& Amphiroa fragilissima & 257 & 165 & 237 \\
\hline & Total & 1228 & 1092 & 1117 \\
\hline
\end{tabular}


Berdasarkan hasil pengamatan, jumlah individu yang paling banyak ialah di stasiun I sebesar 1228 individu. Hal ini dikarenakan pada stasiun I kondisi habitatnya terdapat banyak karang dan didukung oleh faktor lingkungan yang sesuai untuk pertumbuhan makroalga tersebut. Karang merupakan tempat tumbuh yang baik untuk pertumbuhan rumput laut (Johan dkk, 2015).

Berdasarkan Gambar 3 jenis-jenis makroalga di Pantai Cidatu yang mempunyai persentase tertinggi ialah dari kelas Phaeophyceae sebesar $42 \%$ diikuti oleh kelas Rhodophyceae sebesar 33\% dan Chlorophyceae sebesar $25 \%$.

Diagram presentasi jumlah jenis pada masing-masing kelas makroalga dapat terlihat pada gambar 3 di bawah ini.

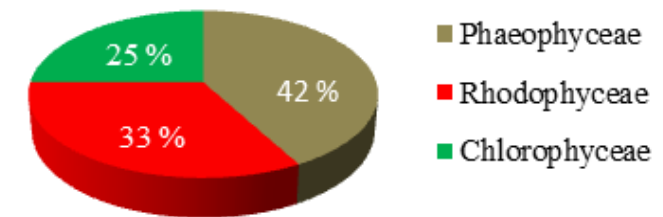

Gambar 3. Presentasi jumlah jenis dari tiap kelas makroalga

Phaeophyceae memiliki kemampuan yang lebih baik untuk beradaptasi karena memiliki lapisan lendir (mucus) yang dapat mengatasi kekurangan air, serta memiliki toleransi terhadap pasang surut yang lama (Johan dkk., 2015), sehingga tingkat persentase Phaeophyceae lebih tinggi dibandingkan dari Chlorophyceae dan Rhodophyceae. Di samping itu dari hasil pengukuran kondisi lingkungan masih dalam kisaran yang optimal untuk pertumbuhan makroalga kecuali intensitas cahaya. Kondisi lingkungan yang telah diukur seperti suhu $\left(29-30^{\circ} \mathrm{C}\right)$, salinitas $(31-32 \%$, dan $\mathrm{pH}$ (7) sedangkan intensitas cahaya yaitu (1939 lux).

\section{Potensi Makroalga Sebagai Obat}

Berdasarkan data yang telah dikumpulkan dari hasil studi literatur terdapat 10 jenis makroalga yang berpotensi sebagai obat. 10 jenis makroalga tersebut meliputi 3 jenis ( 30\%) dari Chlorophyceae, 4 jenis ( $40 \%$ ) dari Phaeophyceae dan 3 jenis $(30 \%)$ dari Rhodophyceae (Gambar 4). Makroalga yang berpotensi sebagai obat dari kelas Chlorophyceae adalah Ulva intestinalis, Ulva reticulata dan Chaetomorpha crassa. Makroalga yang berpotensi sebagai obat dari kelas Phaeophyceae adalah Sargassum polycystum, Sargassum crassifolium, Padina australis, dan Turbinaria decurrens. Sedangkan makroalga dari kelas Rhodophyceae yang berpotensi sebagai obat adalah Gracilaria salicornia, Gracilaria coronopifolia dan Gelidium sp. Marga Ulva bermanfaat sebagai antibakteri dan menurunkan darah tinggi. Marga Padina bermanfaat sebagai antibakteri. Marga Sargassum bermanfaat sebagai antibakteri, antitumor, menurunkan tekanan darah tinggi, dan gangguan kelenjar gondok. Marga Gracilaria bermanfaat sebagai obat gangguan dalam. Gelidium sp. bermanfaat sebagai antibakteri, antijamur, dan gangguan dalam (Kadi, 2004). Data mengenai potensi obat terdapat pada Tabel 2.

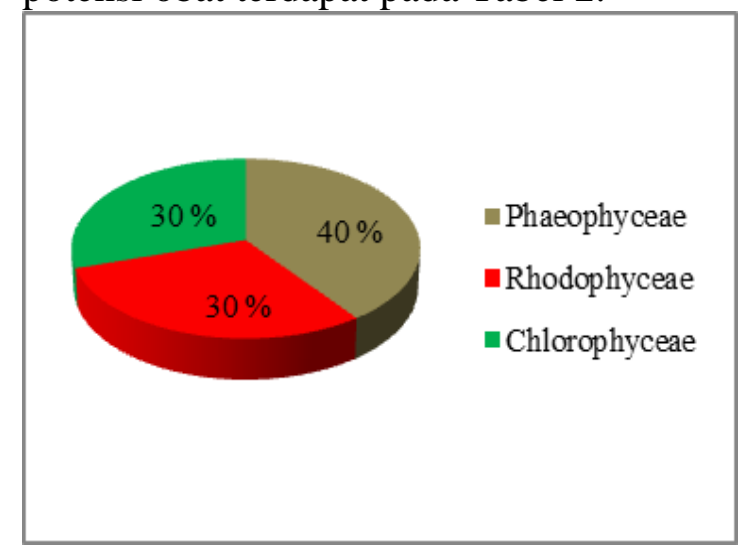

Gambar 4. Presentasi jumlah jenis makroalga berpotensi sebagai bahan obat dari tiap kelas makroalga. 
Tabel 2. Jenis Makroalga Berpotensi Obat di Perairan Pantai Cidatu Kabupaten Pandeglang

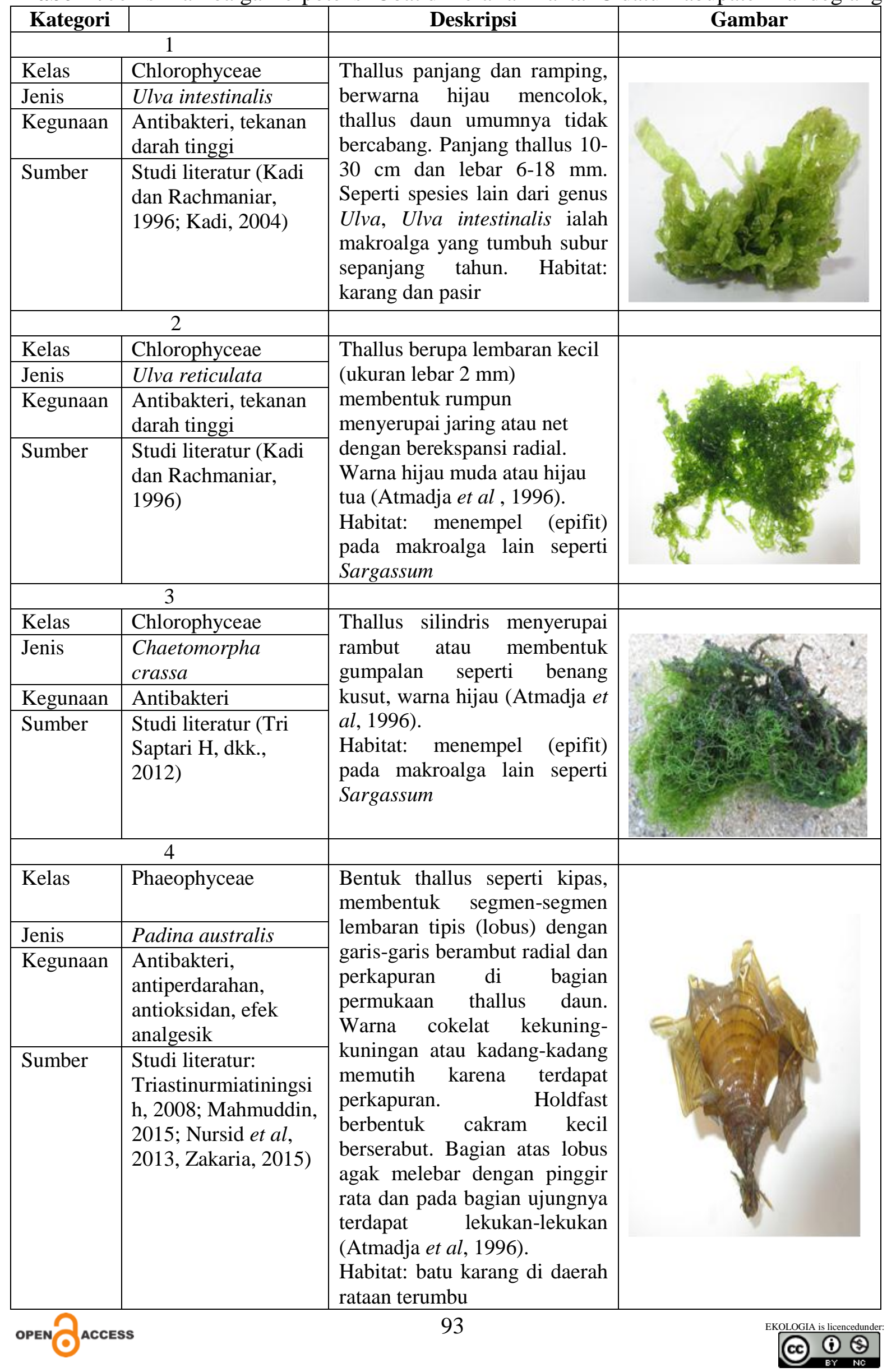


Haris Shobir, Dkk: Keanekaragaman Jenis Makroalga Yang Berpotensi...

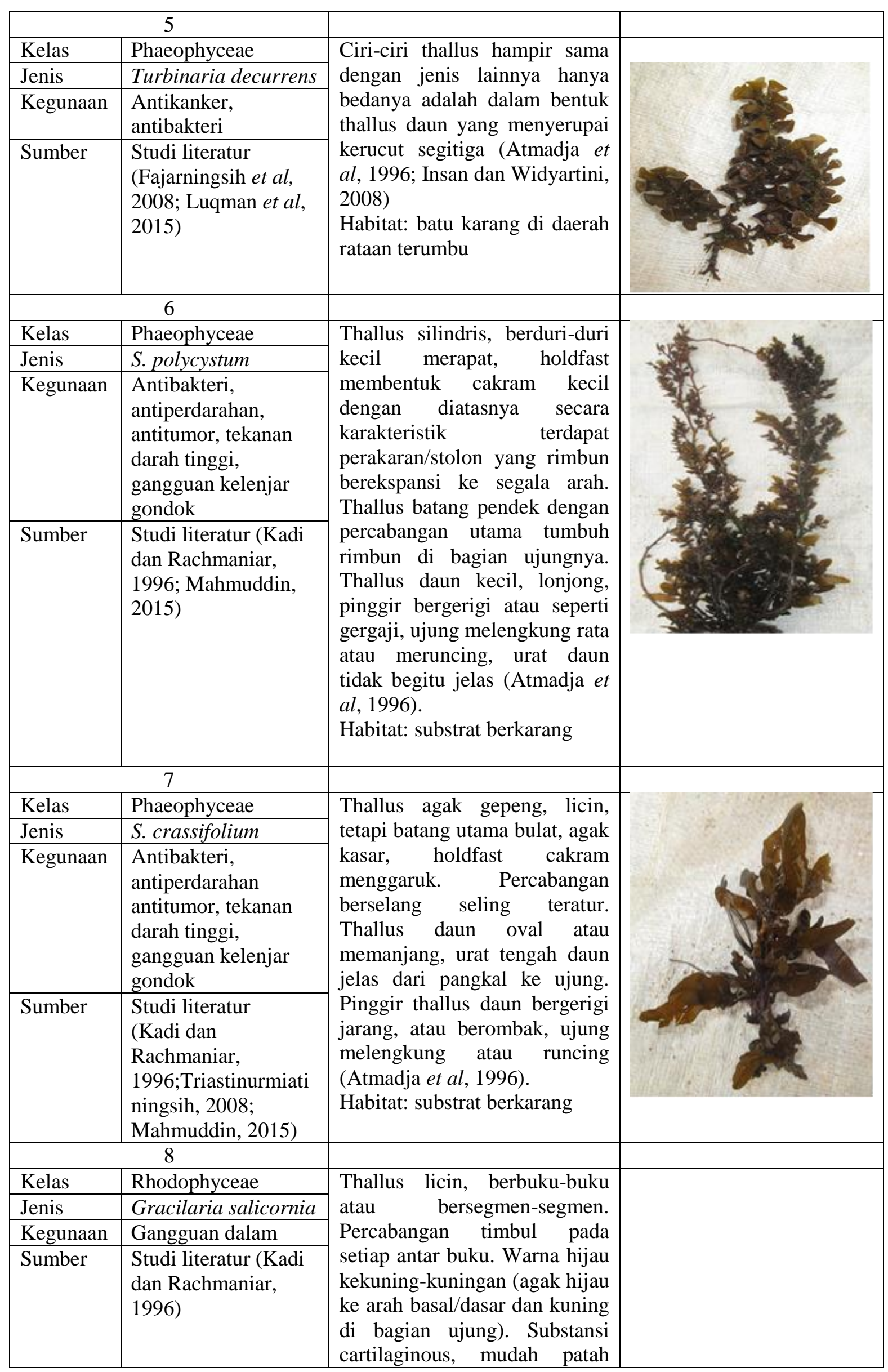




\begin{tabular}{|c|c|c|c|}
\hline & & $\begin{array}{l}\text { (getas/rapuh) (Atmadja et al, } \\
\text { 1996). } \\
\text { Habitat: batu kerikil di daerah } \\
\text { rataan terumbu }\end{array}$ & \\
\hline \multicolumn{4}{|c|}{9} \\
\hline Kelas & Rhodophyceae & \multirow{4}{*}{$\begin{array}{l}\text { Thallus silindris, licin, } \\
\text { menempel pada substrat } \\
\text { dengan cakram kecil. } \\
\text { Percabangan mendua bagian } \\
\text { (dichotomous) berulang-ulang. } \\
\text { Umumnya rimbun pada porsi } \\
\text { bagian atas rumpun (Atmadja } \\
\text { et al, 1996). } \\
\text { Habitat: batu di daerah rataan } \\
\text { terumbu }\end{array}$} & \\
\hline Jenis & G. coronopifolia & & \\
\hline Kegunaan & Gangguan dalam & & \\
\hline Sumber & $\begin{array}{l}\text { Studi literatur (Kadi } \\
\text { dan Rachmaniar, } \\
\text { 1996) }\end{array}$ & & \\
\hline \multicolumn{4}{|c|}{10} \\
\hline Kelas & Rhodophyceae & \multirow{4}{*}{$\begin{array}{l}\text { Thallus berwarna merah } \\
\text { kecokelatan (pirang), bentuk } \\
\text { tubuh seperti rumput atau } \\
\text { semak. Sepanjang tubuhnya } \\
\text { ditumbuhi bagian yang seperti } \\
\text { duri. Alga ini memiliki } \\
\text { holdfast yang berfungsi } \\
\text { sebagai tempat melekat pada } \\
\text { terumbu karang sehingga dapat } \\
\text { beradaptasi dengan gerakan } \\
\text { ombak pada zona pasang surut. } \\
\text { Habitat: substrat berkarang di } \\
\text { daerah pasang surut (intertidal) }\end{array}$} & \\
\hline Jenis & Gelidium sp. & & \\
\hline Kegunaan & $\begin{array}{l}\text { Gangguan dalam, } \\
\text { antibakteri, antivirus, } \\
\text { antijamur }\end{array}$ & & \\
\hline Sumber & $\begin{array}{l}\text { Studi literatur } \\
\text { (Atmadja, 1992; } \\
\text { Kadi dan } \\
\text { Rachmaniar, 1996) }\end{array}$ & & 8 \\
\hline
\end{tabular}

Ulva berkhasiat untuk obat darah tinggi (Kadi, 2004). Selain itu, Ulva juga dapat digunakan sebagai salad dan sup. Ulva memiliki kandungan Fe yang sangat tinggi. Ulva banyak dikonsumsi di China, Filipina, Chili dan Hindia Barat. Selain itu, Ulva juga merupakan sumber vitamin $\mathrm{C}$, protein, asam folat dan beberapa jenis mineral, seperti $\mathrm{Ca}$, $\mathrm{K}, \mathrm{Mg}, \mathrm{Na}, \mathrm{Cu}, \mathrm{Fe}$ dan Zn (Rasyid, 2004).

Marga Sargassum dan Padina memiliki khasiat sebagai antibakteri dan antiperdarahan, selain itu juga marga Sargassum berkhasiat sebagai antitumor, tekanan darah tinggi dan gangguan kelenjar gondok (Mahmuddin, 2015). Sargassum dan Padina mengandung senyawa tanin dan flavonoid yang berfungsi sebagai hemostatik dengan arti lain menghentikan perdarahan (Mahmuddin, 2015). Padina juga memiliki efek analgesik yaitu efek bekerjanya penghilang rasa nyeri (Zakaria, 2015). Hasil penelitian Nursid dkk., (2013), Padina australis memiliki aktivitas antioksidan. Menurut Rasyid (2004), Sargassum merupakan salah satu sumber yodium, vitamin C, protein dan asam folat. Sargassum digunakan sebagai bahan makanan di Jepang dan Korea. 
Marga Gracilaria diketahui berkhasiat sebagai obat penyakit gangguan dalam. Gracilaria verrucosa dapat mengobati gangguan saluran kemih dan gondokan (Widyartini, 2015). Dibidang obat-obatan alami rumput laut jenis Gracilaria lichenoides dapat dimanfaatkan sebagai obat desentri/diare dan obat gondok (Kadi dan Rachmaniar, 1996). Marga Gelidium berkhasiat untuk gangguan dalam, antijamur, antibakteri dan antivirus. Gelidium anursii mengobati sakit perut. Penelitian terhadap Gelidium dan spesies turunannya juga membantu mengembangkan teknologi pemanfaatan baru rumput laut. Misalnya sebagai bahan baku agar-agar, pulp, atau bioetanol. Selain itu juga sebagai peredam $\mathrm{CO}_{2}$ sebagai salah satu bagian clean development management. Cara ini menjadi bagian upaya mengatasi pemanasan global (Widyartini, 2015).

\section{Indeks Keanekaragaman}

Keanekaragaman jenis pada suatu komunitas adalah refleksi dari variasi jenis dan kemerataan individu yang ditemukan dalam suatu perairan (Yaqin dkk, 2011). Dari hasil perhitungan yang telah dilakukan, nilai indeks keanekaragaman pada stasiun I sebesar 2,102 dan pada stasiun II sebesar 2,267 serta pada stasiun III sebesar 2,138 maka rata-rata indeks nilai keanekaragaman jenis di perairan Pantai Cidatu dikategorikan sedang yaitu 2,169. Keanekaragaman jenis lebih rendah dibandingkan dengan hasil penelitian di Pantai Bayah, Banten. Indeks keanekaragaman di Pantai Bayah yaitu 4,340 (Tri Saptari dkk, 2012). Menurut Nurkiama dkk., (2015), keanekaragaman jenis makroalga di daerah pasang surut (intertidal) antara lain disebabkan pula oleh heterogenitas substratnya. Di tempat-tempat yang memiliki substrat pecahan karang batu mati, karang masif dan pasir yang lebih stabil, mempunyai keanekaragaman alga yang lebih tinggi dibandingkan dengan tipe substrat pasir dan lumpur saja. Dari hasil pengamatan, substrat yang ada di perairan Pantai Cidatu tidak begitu beragam sehingga nilai dari indeks keanekaragaman jenis tidak tinggi. Selain itu juga, terdapat perbedaan jumlah individu dari tiap-tiap spesies makroalga yang bervariasi. Beberapa spesies memiliki jumlah individu yang banyak tetapi beberapa spesies lain memiliki jumlah individu yang sedikit. Adanya perbedaan jumlah individu tersebut mempengaruhi nilai indeks keanekaragaman jenis.

\section{KESIMPULAN}

Berdasarkan hasil penelitian yang telah dilakukan dapat disimpulkan bahwa makroalga yang berpotensi sebagai obat di perairan Pantai Cidatu dari kelas Chlorophyceae (Ulva intestinalis, Ulva reticulata, Chaetomorpha crassa), dari kelas Phaeophyceae (Padina australis, Sargassum polycystum, Sargassum crassifolium, Turbinaria decurrens) dan 3 jenis dari kelas Rhodophyceae (Gracilaria salicornia, Gracilaria coronopifolia, Gelidium sp). Potensinya sebagai antibakteri, antijamur, antikanker, antivirus, antitumor, menurunkan tekanan darah tinggi, mengobati gangguan kelenjar gondok, dan gangguan dalam tubuh. Nilai Indeks Keanekaragaman jenis 2,169 termasuk kategori sedang.

\section{DAFTAR PUSTAKA}

Atmadja, W.S., A. Kadi, Soelistijo dan R. Satari. (1996). Pengenalan Jenisjenis Rumput Laut Indonesia. Puslitbang Oseanologi LIPI. Jakarta.

English, S., C. Wilkinson and V. Baker. (1994). Survey Manual for Tropical Marine Resources. Australian Institute of Marine Science. Townsville.

Tri Saptari H, Triastinurmiatiningsih dan Irfan A. (2012). Keanekaragaman dan Pemanfaatan Rumput Laut di Pantai Bayah, Banten. Jurnal Omni-Akuatika. 11(6) hal:1-8

Insan, A.I. dan Widyartini D.S. (2008). Jenis-jenis Rumput Laut yang Berpotensi Sebagai Obat yang Tumbuh pada Berbagai Substrat di 
Pantai Ranababakan Nusakambangan Cilacap. Seminar Nasional PTTI. Cibinong, Bogor: 21-23 Oktober 2008.

Johan, O., Erlania., dan I Nyoman Radiarta. (2015). Hubungan Substrat Dasar Perairan Dengan Kehadiran Rumput Laut Alam di Perairan Ujung Genteng, Sukabumi, Jawa Barat. Jurnal Riset Akuakultur. 10(4) hal: 609-618.

Kadi, A dan Rachmaniar R. (1996). Potensi Rumput Laut Sebagai Bahan Obat Alami dalam Prosiding Simposium Penelitian Bahan Obat Alami VIII. Perhimpunan Peneliti Bahan Obat Alami (PERHIBPA). Puslitbang Oseanologi LIPI.

Kadi, A. (2004). Potensi Rumput Laut di Beberapa Perairan Pantai Indonesia. Jurnal Oseana. 29(4) hal: 25-36.

Mahmuddin, I. (2015). Efek Antiperdarahan Alga Coklat (Sargassum sp. dan Padina sp.) pada Luka Potong Ekor Mencit (Mus musculus) (Pilot Study). Skripsi. Universitas Hasanudin. Makassar.

Merdekawati, W. dan A.B. Susanto. (2009). Kandungan dan Komposisi Pigmen Rumput Laut serta Potensinya Untuk Kesehatan. Jurnal Squalen. 4(2) hal: 41-47.

Nurkiama, L., Muzahar dan Fadhliyah Idris. (2015). Keanekaragaman dan Pola Sebaran Makroalga di Perairan Laut Pulau Pucung Desa Malang Rapat Kabupaten Bintan. FIKP UMRAH: Jurusan Ilmu Kelautan.

Nursid, M., Thamrin Wikanta dan Rini Susilowati. (2013). Aktivitas Antioksidan, Sitotoksisitas dan Kandungan Fukosantin Ekstrak Rumput Laut Coklat Dari Pantai Binuangeun, Banten. JPB Kelautan dan Perikanan. 8(1) hal 73-84.

Pratama, A., W. I. Rachmani., dan L. S. Mulyawati. (2014). Identifikasi Keterkaitan Kawasan Wisata
Pantai Carita Terhadap Usaha Pariwisata di Kecamatan Carita Kabupaten Pandeglang Provinsi Banten. FT UNPAK: Program Studi Perencanaan Wilayah dan Kota.

Rasyid, A. (2004). Berbagai Manfaat Algae. Jurnal Oseana. 29(3) hal: 9-15.

Saptasari, M. (2010). Variasi Ciri Morfologi dan Potensi Makroalga Jenis Caulerpa di Pantai Kondang Merak Kabupaten Malang. Jurnal El-Hayah. 1(2) hal: 19-22.

Stephanie, W., Gunawan W.S. dan Sunaryo. (2014). Distribusi Makroalgae di Wilayah Intertidal Pantai Krakal, Kabupaten Gunung Kidul, Yogyakarta. Journal of Marine Research. 3(4) hal: 633-641.

Subagja, M.A. (2010). Peta Pandeglang. http://www.wildankamil09.com diakses tanggal 14 Mei 2016.

Sulistijo. (2009). Buku Modul Rumput Laut (Makroalga). Pusat Penelitian Oseanografi Lembaga Ilmu Pengetahuan Indonesia. Jakarta.

Triastinurmiatiningsih dan Tri Saptari Haryani, (2008). Potensi Rumput Laut Di Pantai Bayah Kabupaten Lebak,Banten Sebagai Antibakteri Escherichia Coli. Jurnal Matematika, Sains, dan Teknologi. Vol. 9 (1): 37-43

Widyartini, D.S. (2015). Potensi dan Keampuhan Rumput Laut Sebagai Obat Tradisional.

http:bio.unsoed.ac.id. 28 Mei 2016.

Winarno, F,G. 1996. Teknologi Pengolahan Rumput Laut. Pustaka Sinar Harapan. Jakarta.

Yaqin, K., Ikbal Burhanuddin dan Wasir Samad. (2011) Biodiversity of Seaweed and Their Metal Contents from Littoral Zone of South Sulawesi Waters. Jurusan Perikanan Fakultas Ilmu Kelautan dan Perikanan Universitas Hasanuddin. Makassar.

Zakaria, S.N.A. (2015). Identifikasi Efek Analgesik Ekstrak Alga Coklat 
Haris Shobir, Dkk: Keanekaragaman Jenis Makroalga Yang Berpotensi...

Padina sp. Pada Mencit (Mus

Hasanuddin. Makassar.

Musculus). Skripsi. Universitas 